\title{
Approach, Avoidance, and Coping With Stress
}

\author{
Susan Roth and Lawrence J. Cohen \\ Duke University
}

\begin{abstract}
The study of stress and coping points to two concepts central to an understanding of the response to trauma: approach and avoidance. This pair of concepts refers to two basic modes of coping with stress. Approach and avoidance are simply metaphors for cognitive and emotional activity that is oriented either toward or away from threat. An approach-avoidance model of coping is presented in the context of contemporary theoretical approaches to coping. The research literature on coping effectiveness, including evidence from our laboratory, is discussed, and speculations are made about the implications for future research.
\end{abstract}

The study of stress and coping has become quite popular in recent years, particularly in regard to traumatic life events. Although the area is broad and the coping process is complex, there is a striking coherence in much of the literature. This coherence is based on two concepts central to an understanding of coping with trauma: approach and avoidance. In its simplest form, this pair of concepts refers to two basic orientations toward stressful information, or two basic modes of coping with stress. Approach and avoidance are shorthand terms for the cognitive and emotional activity that is oriented either toward or away from threat.

In this article we will present the case for utilizing the concepts of approach and avoidance to provide a coherent theoretical structure to our understanding of coping with stress. Several different formulations of the approach-avoidance dimension will be reviewed, followed by a brief review of the coping effectiveness literature. Several studies from our laboratory will be used to illustrate the relationship between coping and outcome. Finally, a general approach-avoidance model of coping will be presented, with suggestions for further research to corroborate or extend the theory.

The study of coping with stress has been split into two areas: anticipation of future stressful events and recovery from trauma. These areas have been kept remarkably distinct in both theory and research on coping. Although there are clearly important differences between the two cases, we have chosen not to emphasize this distinction. For any given stress, anticipation and recovery are not always clearly separable; dealing with a trauma involves coming to terms with the event itself and with the threat of recurrence in the future. More important,

Correspondence concerning this article should be sent to Susan Roth, Department of Psychology, Duke University, Durham, NC 27706. we have identified the same processes as central to coping in both anticipation and recovery periods.

\section{Approach-Avoidance Formulations}

The approach-avoidance distinction is not new, having historical roots in psychoanalytic theories of defense and working through (e.g., Freud, 1915/1957), and in views of conflict from the behavioral (e.g., Hovland \& Sears, 1938; Miller, 1944) and phenomenological (e.g., Lewin, 1951) traditions. In the more recent literature on coping with stress, approach-avoidance distinction is a core idea. One is struck by the extent to which the concepts of approach and avoidance underlie the personality or individual difference variables studied in the anticipatory threat literature, and also the dimensions of coping studied in traumatic stress reaction research. Table 1 briefly describes 14 of these coping formulations.

In the anticipatory threat literature, the repressionsensitization distinction is paradigmatic of the approachavoidance dimension of individual difference: Repression involves an avoidance of anxiety-arousing stimuli and their consequences and is a general orientation away from threat. Sensitization, on the other hand, is the approach toward anxiety-arousing stimuli and their consequences and is an orientation toward threat. Although, as we shall see, there is no clear-cut evidence regarding the effects of individual differences along the approach and avoidance dimensions, the issues for coping and adaptation seem to be the following: Avoidant strategies seem useful in that they may reduce stress and prevent anxiety from becoming crippling. Approach strategies, on the other hand, allow for appropriate action and/or the possibility for noticing and taking advantage of changes in a situation that might make it more controllable. Approach strategies also allow for ventilation of affect.

Individual differences along the approach-avoidance dimension have also been a focus of study in the traumatic stress reaction research. For example, Shontz (1975) discussed fragmentation versus containment in response to illness, whereas McGlashan, Levy, and Carpenter (1975) referred to integration and sealing over as two distinct styles of recovery from schizophrenia. To illustrate, fragmentation is a form of denial in which people split themselves off from their illness, resulting in an unstable selfsystem. Containment is the incorporation of threat into an integrated self-structure, without overwhelming the self.

Horowitz's $(1976,1979)$ formulation of the approach-avoidance dimension in response to stress is the most fully developed and will be discussed in more detail. 
Table 1

Summary of Approach-Avoidance Coping Formulations

\begin{tabular}{|c|c|c|c|}
\hline Coping formulation & Avoidance & Approach & Measurement \\
\hline $\begin{array}{l}\text { Perceptual defense- } \\
\text { perceptual vigilance } \\
\text { (Bruner \& Postman, 1947) }\end{array}$ & $\begin{array}{l}\text { Relative deficit in perceiving } \\
\text { threatening stimuli }\end{array}$ & $\begin{array}{l}\text { Relative readiness to } \\
\text { perceive threatening } \\
\text { stimuli }\end{array}$ & $\begin{array}{l}\text { Tachistoscope word } \\
\text { recognition paradigm }\end{array}$ \\
\hline $\begin{array}{l}\text { Avoidance-vigilance (Cohen } \\
\text { \& Lazarus, 1973; Janis, } \\
\text { 1958, 1977, 1982) }\end{array}$ & $\begin{array}{l}\text { Procrastination, giving up of } \\
\text { personal responsibility, } \\
\text { inadequate search of } \\
\text { environmental cues, } \\
\text { restricting thought about } \\
\text { the stressor, and failure to } \\
\text { appraise the situation and } \\
\text { make contingency plans }\end{array}$ & $\begin{array}{l}\text { Alertness; self-responsibility; } \\
\text { thorough, active } \\
\text { searching; seeking } \\
\text { knowledge; careful } \\
\text { appraisal and planning }\end{array}$ & $\begin{array}{l}\text { Interviews or observer } \\
\text { ratings }\end{array}$ \\
\hline $\begin{array}{l}\text { Repression-sensitization } \\
\text { (Bell \& Byrne, 1978; } \\
\text { Byrne, 1964) }\end{array}$ & $\begin{array}{l}\text { Avoidance of anxiety- } \\
\text { arousing stimuli and their } \\
\text { consequents, selective } \\
\text { inattention and forgetting, } \\
\text { and low anxiety }\end{array}$ & $\begin{array}{l}\text { Orientation toward anxiety- } \\
\text { arousing stimuli and their } \\
\text { consequents, selective } \\
\text { attention and recall, and } \\
\text { high anxiety }\end{array}$ & MMPI subscale \\
\hline $\begin{array}{l}\text { Repression-sensitization } \\
\text { (Gudjonsson, 1981; } \\
\text { Houston \& Hodges, 1970) }\end{array}$ & $\begin{array}{l}\text { Low subjective distress plus } \\
\text { high electrodermal } \\
\text { indicators of distress }\end{array}$ & $\begin{array}{l}\text { High subjective distress plus } \\
\text { low electrodermal } \\
\text { indicators of distress }\end{array}$ & $\begin{array}{l}\text { Discrepancy between } \\
\text { psychological and } \\
\text { physiological measures of } \\
\text { arousal during a stressful } \\
\text { laboratory experience }\end{array}$ \\
\hline $\begin{array}{l}\text { Nonvigilant-vigilant (Averill \& } \\
\text { Rosenn, 1972) }\end{array}$ & $\begin{array}{l}\text { Preferences for unsignaled } \\
\text { shock, even when } \\
\text { avoidance possible }\end{array}$ & $\begin{array}{l}\text { Preference for signaled } \\
\text { shock, even when no } \\
\text { avoidance possible }\end{array}$ & $\begin{array}{l}\text { While awaiting shock in a } \\
\text { laboratory situation, } \\
\text { subjects could either } \\
\text { listen to music or for a } \\
\text { warning signal }\end{array}$ \\
\hline $\begin{array}{l}\text { Selective inattention- } \\
\text { selective attention } \\
\text { (Kahnemann, 1973) }\end{array}$ & $\begin{array}{l}\text { Inattention to selected (e.g., } \\
\text { threatening) elements of } \\
\text { the perceptual field }\end{array}$ & $\begin{array}{l}\text { Attention to threatening } \\
\text { elements of perceptual } \\
\text { field }\end{array}$ & $\begin{array}{l}\text { Memory and recognition } \\
\text { tasks and perceptual } \\
\text { techniques such as } \\
\text { monitoring eye movement }\end{array}$ \\
\hline $\begin{array}{l}\text { Inaccurate-accurate } \\
\text { expectations (Johnson \& } \\
\text { Leventhal, 1974) }\end{array}$ & $\begin{array}{l}\text { Not having accurate } \\
\text { information about what to } \\
\text { expect regarding a } \\
\text { threatening situation }\end{array}$ & $\begin{array}{l}\text { Having accurate information } \\
\text { about what to expect } \\
\text { regarding a threatening } \\
\text { situation }\end{array}$ & $\begin{array}{l}\text { Instructions to improve } \\
\text { accuracy of expectations }\end{array}$ \\
\hline $\begin{array}{l}\text { Reducers-augmenters } \\
\text { (Petrie, 1978) }\end{array}$ & $\begin{array}{l}\text { Ignoring warning signals and } \\
\text { information about } \\
\text { hazards; tolerance for } \\
\text { pain }\end{array}$ & $\begin{array}{l}\text { Attending to warning } \\
\text { signals; intolerance for } \\
\text { pain }\end{array}$ & $\begin{array}{l}\text { Estimation of lengths and } \\
\text { weights }\end{array}$ \\
\hline $\begin{array}{l}\text { Blunting-monitoring (Miller, } \\
\text { 1980; Miller \& Mangan, } \\
\text { 1983) }\end{array}$ & $\begin{array}{l}\text { Seeking distraction, } \\
\text { relaxing, denying threat, } \\
\text { practicing detachment and } \\
\text { intellectualization }\end{array}$ & $\begin{array}{l}\text { Vigilance, anxiety, and } \\
\text { orientation toward threat }\end{array}$ & $\begin{array}{l}\text { Listening to music or to } \\
\text { warning signal; self-report } \\
\text { of behavioral preference } \\
\text { in hypothetical threatening } \\
\text { situation }\end{array}$ \\
\hline $\begin{array}{l}\text { Rejection-attention } \\
\text { (Mullen \& Suls, 1982) }\end{array}$ & $\begin{array}{l}\text { Orientation away from } \\
\text { stressor and one's } \\
\text { reactions to it }\end{array}$ & Orientation toward stressor & $\begin{array}{l}\text { Formulation from literature } \\
\text { review }\end{array}$ \\
\hline $\begin{array}{l}\text { Sealing over-integration } \\
\text { (McGlashan, Levy, \& } \\
\text { Carpenter, 1975) }\end{array}$ & $\begin{array}{l}\text { In regard to recovery from a } \\
\text { schizophrenic episode, a } \\
\text { lack of curiosity about the } \\
\text { experience, a shifting of } \\
\text { responsibility onto others, } \\
\text { a negative view of the } \\
\text { episode, an isolation of } \\
\text { the episode from the rest } \\
\text { of the person's life, and a } \\
\text { failure to grow from the } \\
\text { experience }\end{array}$ & $\begin{array}{l}\text { Curiosity about the } \\
\text { experience, taking self- } \\
\text { responsibility, positive } \\
\text { view of episode, } \\
\text { incorporation of episode } \\
\text { into the person's life }\end{array}$ & $\begin{array}{l}\text { Clinician ratings of patient } \\
\text { interviews }\end{array}$ \\
\hline
\end{tabular}

(table continued) 
Table 1 (continued)

\begin{tabular}{|c|c|c|c|}
\hline Coping formulation & Avoidance & Approach & Measurement \\
\hline $\begin{array}{l}\text { Retreat-encounter } \\
\text { (Shontz, 1975) }\end{array}$ & $\begin{array}{l}\text { Avoidance of thinking about } \\
\text { a trauma or its } \\
\text { consequences }\end{array}$ & $\begin{array}{l}\text { Cognitive and emotional } \\
\text { acknowledgment of } \\
\text { trauma }\end{array}$ & $\begin{array}{l}\text { Clinical evaluations of } \\
\text { patients with severe } \\
\text { disabilities }\end{array}$ \\
\hline $\begin{array}{l}\text { Fragmentation-containment } \\
\text { (Shontz, 1975) }\end{array}$ & $\begin{array}{l}\text { Splitting oneself off from } \\
\text { one's illness }\end{array}$ & $\begin{array}{l}\text { Integration of threat into the } \\
\text { self-system }\end{array}$ & $\begin{array}{l}\text { Clinical evaluations of } \\
\text { patients with less severe } \\
\text { disabilities }\end{array}$ \\
\hline $\begin{array}{l}\text { Denial-intrusion (Horowitz, } \\
\text { 1976; 1979; Zilberg, } \\
\text { Weiss, \& Horowitz, 1982) }\end{array}$ & $\begin{array}{l}\text { Numbness, removal of } \\
\text { material from } \\
\text { consciousness and from } \\
\text { memory, behavioral } \\
\text { constriction, and } \\
\text { avoidance of reminders of } \\
\text { the stressor }\end{array}$ & $\begin{array}{l}\text { Sleep disturbance, waves of } \\
\text { feelings, images or } \\
\text { thoughts that pop into } \\
\text { one's head, and a } \\
\text { tendency to be reminded } \\
\text { of the event by virtually } \\
\text { any stimulus }\end{array}$ & $\begin{array}{l}\text { Self-report symptom check } \\
\text { list (Impact of Events } \\
\text { Scale) following a } \\
\text { traumatic experience }\end{array}$ \\
\hline
\end{tabular}

In his model, the memory of a trauma can neither be excluded from consciousness nor integrated fully. The mind has an active memory that has an "intrinsic tendency towards repetition of representations of contents until . . . completion of cognitive processing" (p. 93, italicized in original). In other words, information that is "unacceptable," such as the death of a loved one, is prevented from being completely processed, but remains in active memory, exerting a constant pressure toward processing.

There are two motivating principles in Horowitz's model. Denial (characterized by numbness, removal of material from consciousness, and avoidance of reminders of the stressor) is motivated by the need to protect the ego from the overwhelming power of the stressor. The need to ultimately accommodate to the reality of the stressor motivates the working-through process. Why cannot denial simply be complete, obviating the need for working through? The answer lies in two negative consequences of denial. The first consequence is failing to perceive or take advantage of opportunities to escape from the stressful situation. The second negative consequence of denial is a buildup of pressure in the active memory, resulting in intrusions (e.g., nightmares, waves of feelings, and being reminded of the stressor by almost any stimulus).

Over time, oscillating periods of denial and intrusions become less intense, with an eventual working through of the stressful material. Shontz (1975) presented a similar model of coping with physical disabilities and severe illnesses. In his model there is a cyclical alternation between retreat and encounter, where retreat is the avoidance of thinking about the trauma and its consequences and encounter is a cognitive and emotional approach to the stressor. Shontz described a pattern of response to disability in which intense periods of encounter (marked by shock, emotional flooding, and despair) and retreat (a reaction against the consequences of encounter) are gradually replaced by a more or less stable equilibrium. The ideal resolution of this pattern is acknowledgment, in which the threat is safely incorporated into an "integrated self structure" (Shontz, 1975, p. 115). However, if ac- knowledgment does not occur, the self can either be overwhelmed by the threat or the person can become fragmented, splitting the illness off from the self.

Both Shontz's idea of acknowledgment and Horowitz's idea of working through suggest that there are schemata or principles that people have that prevent the uncomplicated assimilation of threatening material. This set of principles includes such basic concepts as: I do not do bad things; I am intact and invulnerable; there is a just world; my world has meaning and coherence; and I am in control of my life. If someone kills civilians in Vietnam, has a severe accident, is raped, has a child with leukemia, or has a psychotic episode, then one or more of these concepts is threatened. It is the threat to these concepts that inhibits the information from being incorporated.

\section{Consistency of Coping Styles}

Table 1 includes two different types of approach-avoidance formulations. One category includes formulations that focus on individual styles of coping with stress, and the other includes those that specify a universal process of coping. The latter category is by far the smaller and includes the work of Shontz and the work of Horowitz and his colleagues. These two types of formulations are not incompatible. Descriptions of universal processes focus on commonalities in response to stress and present a prototypic case of coping, allowing for a great deal of individual variation in the intensity, duration, and relative importance of particular responses. The emphasis of the remaining formulations is on this individual variation.

Those coping formulations that focus on individual styles of coping invariably contrast approach with avoidance; that is, people are either approachers or avoiders. The formulations differ, however, in the extent to which they assume a consistency in style over time and across situations. The repression-sensitization scale, for example, was designed to measure a personality trait. However, the scale was found to have a correlation with manifest anxiety as high as its test-retest reliability (Bell \& Byrne, 1978). In two recent studies from our own laboratory, a high degree of consistency over time was found in subjects' 
coping responses to abortion (Cohen \& Roth, 1984) and cancer (Manuel \& Roth, 1984). However, although scores on both the approach measures and the avoidance measures were highly consistent, they were not mutually exclusive; that is, people could not simply be characterized as either approachers or avoiders because nearly all subjects used some strategies from each category. This is what we would expect, in fact, in view of accumulated knowledge about universal processes of coping.

Further support for the idea of consistent individual differences between people on the approach and avoidance dimensions comes from work by Averill and Rosenn (1972). In this experiment, vigilance was defined as listening for a warning signal during the anticipation of electric shock; nonvigilance was defined as ignoring the warning signal by listening instead to music. As the subjects awaited the shock, they could switch back and forth between two channels of a tape recorder. One group of subjects could avoid the shock by pressing a button following the warning signal. A second group did not have this option; they could listen vigilantly for the warning signal and hence know when the shock would occur, but they could do nothing to avoid it. Several findings are noteworthy. First, each subject tended to listen either to tone or music with little switching back and forth. Second, although the number of subjects choosing a vigilant coping strategy was affected by the availability of an avoidance response, a large minority of subjects $(23 \%)$ consistently chose to ignore the warning signal even though the shock was easily preventable. Similarly, approximately one-half of the no-avoidance group preferred to listen for the warning signal. Thus, even in situations that might be seen to clearly demand one strategy, some people continue to use another.

The concepts of approach and avoidance are important both for coping formulations focusing on universal processes and for coping formulations focusing on individual differences in style. Furthermore, although there is evidence that in some situations people have a strong preference for either approach or avoidance responses, it is likely to be true more generally that the use of approach and avoidance coping strategies are not mutually exclusive. There can be, for example, a rapid alternation between the two orientations, or certain aspects of threatening material can be avoided while other aspects are approached. Research is sorely needed to bring evidence to bear on the question of individual consistency in coping style across time and situations. Finally, as a group, the various approach-avoidance formulations present a coherent set of ideas about the coping process in general, and about two important dimensions of individual difference, that are ripe for empirical verification.

\section{Approach, Avoidance, and Coping Effectiveness}

Drawing conclusions from the research addressing the question of the effectiveness of approach and avoidance coping strategies is not a simple task. Nonsystematic variation in the literature of conceptualizations of ap- proach and avoidance, measurement approaches, indicators of effectiveness, and stressors compounds the difficulty of understanding the coping process. Some attempts have been made in the literature, however, to extract general principles concerning the consequences of approach and avoidance. There are three important factors in evaluating coping effectiveness: The point in time at which effectiveness is evaluated; the controllability of aspects of the stressful situation; and the fit between coping style and certain demands of the stressful situation. No attempt has been made here to present a thorough review of all research; the citations were chosen to be illustrative.

The most compelling indication of the importance of time of testing comes from the work of Mullen and Suls (1982). They found a consistent pattern across a large number of studies, namely that rejection (avoidance) strategies were found to be effective when outcome measures were immediate or short term, whereas attention (approach) strategies were found to be more effective when the outcome measures were long term. Unfortunately, none of the studies reviewed measured short- and longterm effects with the same subjects, and the authors defined effectiveness only in terms of physical adaptation. However, additional evidence reviewed by Lazarus (1983) is consistent with the notion that denial may be helpful only in a limited time frame and might extract a price later on. Avoidance is often a valuable form of coping during the initial period when emotional resources are limited.

Second, there is evidence to support the hypothesis that avoidance is better than approach if the situation is uncontrollable, whereas approach is better if there is potential control. The implication here is that approach allows one to take advantage of opportunities for control, if these are present. For example, Katz, Weiner, Gallagher, and Hellman (1970) found that avoiders delayed seeking diagnostic evaluations for breast cancer, and thus reduced their chances of effective intervention if they did indeed have cancer. In a similar situation, Staudenmeyer, Kinsman, Dirks, Spector, and Wangaard (1979) found that asthmatics who approached at the onset of an attack had fewer serious attacks than those who avoided. Lazarus (1983) concluded from these and related studies that coping effectiveness depends on the controllability of the situation. Illnesses such as asthma, diabetes, and cancer require vigilance for proper diagnosis or treatment. With other illnesses, such as paralysis, there is no advantage of approach, whereas avoidance serves to reduce anxiety and depression.

The final important factor in coping effectiveness is the fit between coping style or coping preference and certain demands of the situation. This is well illustrated in an experiment by Miller and Mangan (1983). They compared surgery patients who preferred to avoid stressful information with those who tended to seek it out, using two treatment conditions: a higher amount of presurgical information and a low amount. Subjects whose treatment condition was consistent with their preferred strategy had 
less distress than those with a discrepancy between the two. A second example from our own laboratory also suggests the importance of this interaction. Cohen and Roth (1984) found that abortion patients who used approach strategies showed a decrease in reported anxiety over the time from five hours presurgery to immediately postsurgery. Those patients who did not use approach strategies did not decrease significantly in reported anxiety. These findings were interpreted in the context of the counseling that subjects took part in at the abortion clinic during the five-hour presurgery period. This counseling was strongly geared toward approach; that is, the counselors provided educational information about pregnancy, abortion, and birth control and made sure that the patients had made a careful decision about terminating their pregnancy. Thus, the approachers' decrease in anxiety may have been due to a consistency between their preferred style and the counseling methods of the clinic.

Given these general principles concerning the consequences of approach and avoidance, and our earlier discussions of approach-avoidance formulations and coping, we would like to present a framework of coping with stress to guide future research.

\section{Approach, Avoidance, and Coping with Stress}

Coping with stress is a dynamic process. The two basic orientations toward threatening information, approach and avoidance, can vary in primacy across time for an individual, and both modes of coping with stress may be present at any particular time, as when certain aspects of the threatening material are approached, and others are avoided. Then, too, an individual may have a consistent preference for one or the other orientation, even in the face of situational constraints that seem to "demand" something other than the preferred response. It is useful to think in terms of approach and avoidant coping strategies, even though some of the cognitive and emotional activity is clearly not consciously designed. Thus, there can be, for example, an unconscious walling off of threatening material as well as a conscious attempt to keep the material out of awareness. The use of approach and avoidant strategies can be evaluated separately and as they interact in terms of a variety of consequences relevant to coping effectiveness.

We will begin the discussion of coping effectiveness with an articulation of potential costs and benefits of approach and avoidance. These costs and benefits, listed in Table 2, are potential because they may not be realized in a particular case. In regard to avoidance, it seems clear that such strategies can serve to reduce stress and anxiety and allow for a gradual recognition of threat. If one doses oneself with threatening material in a way that prevents it from becoming overwhelming (see, for example, Horowitz, 1979), one is provided with needed time for assimilation of stressful information and for mobilization of efforts to change the environment or provide protection. Partial, tentative, or minimal use of avoidance can lead to increased hope and courage, particularly over a long period of time. One can also achieve a sense of mastery
Table 2

Potential Costs and Benefits of Approach and Avoidance

\begin{tabular}{ccc}
\hline Reaction & \multicolumn{1}{c}{ Benefits } & \multicolumn{1}{c}{ Costs } \\
\hline Approach & $\begin{array}{c}\text { Appropriate action } \\
\text { Ventilation of affect } \\
\text { Assimilation and } \\
\text { resolution of } \\
\text { trauma }\end{array}$ & $\begin{array}{c}\text { Increased distress } \\
\text { Nonproductive worry }\end{array}$ \\
Avoidance & $\begin{array}{c}\text { Stress reduction } \\
\text { Allows for dosing } \\
\text { Increased hope } \\
\text { and courage }\end{array}$ & $\begin{array}{c}\text { Interference with } \\
\text { appropriate action } \\
\text { Emotional numbness } \\
\text { Intrusions of threatening } \\
\text { material }\end{array}$ \\
& & $\begin{array}{c}\text { Disruptive avoidance } \\
\text { behaviors }\end{array}$ \\
& & Lack of awareness of \\
& relationship of \\
& & symptoms to trauma
\end{tabular}

over unpleasant emotions associated with the threatening material.

Thus, in the long run, the positive consequences of avoidance are largely effects that work to facilitate approach. Even in uncontrollable situations where there is no possibility for instrumental behavior, the reduction in stress and anxiety provided by avoidance may not be productive if it prevents an assimilation and resolution of the trauma. In these cases, the potential benefits of avoidance strategies depend on the simultaneous or alternating use of approach strategies for their realization.

The potential benefits of approach are great. In any situation where there is the possibility of affecting the nature of a threat, appropriate action is contingent on approach strategies. An orientation toward threat is necessary if, for example, appropriate action is to be taken at the onset of an asthma attack, or if effective precautions are to be taken to prevent repeated victimizations. Noticing and taking advantage of changes in a situation, such as changes in the controllability of aspects of the situation, also calls for an orientation toward threat. Cognitive and emotional activity that is oriented toward the stressor often results in a fuller experience and expression of emotional distress that has the potential of being beneficial. Indeed, psychodynamic psychotherapy is often aimed at such emotional approach. Finally, assimilation and resolution of threat and trauma into an integrated selfstructure (see, for example, Horowitz, 1979; Shontz, 1975 ) is only possible with approach.

As can be seen in Table 2, there are potential costs associated with both approach and avoidance. In regard to approach, the orientation toward threatening material can lead to increased distress. Also, when there is no possibility for changing the situation or for emotional assimilation of the threat, approach can lead to worrying that is both time consuming and nonproductive.

The potential costs of avoidance are also significant. First, avoidant strategies can interfere with appropriate 
action when there is the possibility of affecting the nature of a threat. Avoidant strategies can also result in emotional numbness, unwanted intrusions of threatening material, and disruptive avoidance behaviors when there is a conscious or unconscious attempt to keep threatening cognitions and affects out of awareness. For example, in the service of keeping threatening material out of awareness, an individual may severely restrict his or her activities so as to avoid reminders of a traumatic incident. Finally, a lack of awareness of the relationship between psychological symptoms and a threat or trauma can be a costly consequence of an orientation away from stress. There can be, for example, a delayed psychological reaction that is not seen correctly as a response to the traumatic event, or even a more immediate reaction with symptoms not obviously related to the trauma in any way. If a connection between the reaction and the trauma is not made, the possibility of adequate treatment and recovery is reduced.

Having articulated the potential costs and benefits of approach and avoidance, we can outline an "ideal" case of coping with stress, an example of how in the best of all possible worlds the coping process might operate at maximum effectiveness. This will provide a standard against which to evaluate what are more likely examples of effective coping in a world of limited resources.

In this ideal case, both modes of coping with stress would be operative, with the benefits of each realized and the costs of each minimized. Thus, adaptive coping efforts would be mobilized and maintained, and there would be a gradual assimilation and resolution of threat or trauma. Although there would be psychological retreats from threatening material, these would not be so consistent or complete as to be costly, and although there would undoubtedly be a significant amount of distress experienced in response to the threat or trauma, this would be time limited due to a successful working-through process.

To be contrasted with this ideal case are instances where certain potential benefits of approach cannot be realized. For example, there are traumas that are so devastating as to render extremely difficult the task of resolution. How easy is it, for example, to integrate the experience of having killed an innocent child while in combat in what now seems like a meaningless war? Or the experience of being a victim of a senseless and brutal crime? If assimilation and resolution of trauma are inhibited, then the relative costs and benefits of approach look quite different than presented in Table 2. Nonproductive worry and distress become more likely consequences of approach, and the potential benefits of avoidance are no longer contingent on the use of approach strategies for their realization.

The difficulty of resolution depends on individual as well as situational factors. Thus, although a particular trauma, such as rape, might not be devastating for everyone, for some its meaning so severely violates certain operating assumptions about male and female roles, or about the relationship between the sexes, as to make integration impossible. Finally, assimilation and resolution of trauma may not be possible because of a person's lim- ited resources. By limited resources we mean both personal resources, such as tolerance for anxiety, and sources of support in the environment.

If avoidance strategies predominate, it becomes important to consider how likely the potential costs of avoidance are. Avoidance is likely to interfere with any appropriate action. This consideration aside, the conditions under which it will be particularly costly to keep threatening material out of awareness can be roughly outlined. The personal significance or meaning of the event will determine to some extent how likely one is to be reminded of threatening material and thus how hard one has to work to keep things out of awareness. Also, the extent to which there are other disturbing thoughts or affects of a similar nature already being kept out of awareness is likely to affect the ease of avoiding. It may well be that in some instances one can put an event to rest successfully by avoidance rather than approach, without any great risk of the unincorporated material surfacing.

\section{Conclusions}

The framework of coping with stress that we have presented has as its central focus the processing of threatening information. Although the framework is not simple, it does oversimplify the two basic orientations toward stress. Thus, for example, there are different types of approach and avoidance, and many different aspects of threat to approach or avoid. There is a clear need for an instrument designed to evaluate approach and avoidance strategies, and we are currently conducting initial reliability studies on such an instrument.

We believe that our speculations about approach, avoidance, and coping effectiveness are consistent with current theory and knowledge and provide a useful framework for understanding what seem like contradictory findings in the literature. For example, denial is likely to be quite beneficial early on in a traumatic episode, or if it is only partial or tentative, or if it occurs in a situation that is both uncontrollable and too threatening to integrate. It is not likely to be beneficial under other conditions. It is possible to use our framework, at least on a posthoc basis, to establish the underlying coherence in a group of seemingly disparate findings.

A model, of course, must go further than merely explaining data after the fact. To make progress in this regard, we recommend the following research strategy. It is important to study one stress or trauma at a time and follow the coping processes over time. With each stress or trauma one could evaluate relevant instrumental coping behaviors, if any, as well as limitations on the possibility of assimilation, accommodation, and resolution of threat. One could also assess the likely ease of putting an event to rest through avoidance by, for example, determining likely meanings associated with the event. The purpose of this research strategy is for the investigation of effective coping strategies to proceed in the context of knowledge of critical characteristics of stressful events.

Finally, we believe our speculations about approach, 
avoidance, and coping effectiveness provide a useful framework for conceptualizing stress-related pathology and its treatment. For example, it seems clear that a lack of flexibility in regard to the use of both approach and avoidance strategies is not adaptive. Unfortunately, it also seems clear that it is not an easy matter to make "approachers" avoid or "avoiders" approach (e.g., Averill \& Rosen, 1972; Miller \& Mangan, 1983). Again, we think that the study of disorder and treatment will proceed most productively if it occurs in the context of the extensive evaluation of the process of coping with individual stressors.

\section{REFERENCES}

Averill, J. R., \& Rosenn, M. (1972). Vigilant and nonvigilant coping strategies and psychophysiological stress reactions during anticipation of electric shock. Journal of Personality and Social Psychology, 23, 128-141.

Bell, P., \& Byrne, D. (1978). Repression-sensitization. In H. London \& J. Exner (Eds.), Dimensions of personality (pp. 449-485). New York: Wiley.

Bruner, J. S., \& Postman, L. (1947). Emotional selectivity in perception and reaction. Journal of Personality, 16, 69-78.

Byrne, D. (1964). Repression-sensitization as a dimension of personality. In B. A. Maher (Ed.), Progress in experimental personality research (Vol. 1, pp. 169-220). New York: Academic Press.

Cohen, F., \& Lazarus, R. S. (1973). Active coping processes, coping dispositions, and recovery from surgery. Psychosomatic Medicine, 35 . 375-389.

Cohen, L., \& Roth, S. (1984). Coping with abortion. Journal of Human Stress, 10, 140-145.

Freud, S. (1957). Instincts and their vicissitudes. In J. Strachey (Ed.), Standard edition of the complete psychological works of Sigmund Freud (pp. 111-142). London: Hogarth. (Original work published 1915)

Gudjonsson, G. H. (1981). Self-reported emotional disturbance and its relation to electrodermal reactivity, defensiveness, and trait anxiety. Personality and Individual Differences, 2, 47-52.

Horowitz, M. (1976). Stress response syndromes. New York: Aronson.

Horowitz, M. (1979). Psychological response to serious life events. In V. Hamilton \& D. M. Warburton (Eds.), Human stress and cognition: An information processing approach (pp. 237-265). Chichester, England: Wiley.

Houston, B. K., \& Hodges, W. F. (1970). Situational denial and performance under stress. Journal of Personality and Social Psychology, I6, 726-730.
Hovland, C. I., \& Sears, R. R. (1938). Experiments on motor conflict. Part I: Types of conflict and their modes of resolution. Journal of Experimental Psychology, 23, 447-493.

Janis, I. L. (1958). Psychological stress. New York: Wiley.

Janis, I. L. (1977). Decision making. New York: Free Press.

Janis, I. L. (1982). Stress inoculation in health care: Theory and research. In D. Meichenbaum \& M. Jaremko (Eds.), Stress prevention and management (pp. 67-100). New York: Plenum.

Johnson, J. E., \& Leventhal, H. (1974). The effects of accurate expectations and behavioral instructions on reactions during a noxious medical examination. Journal of Personality and Social Psychology, 29, 710-718.

Kahnemann, D. (1973). Attention and effort. Englewood Cliffs, NJ: Prentice-Hall.

Katz, J., Weiner, H., Gallagher, T., \& Hellman, L. (1970). Stress, distress, and ego defenses. Archives of General Psychiatry, 23, 131-142.

Lazarus, R. S. (1983). The costs and benefits of denial. In S. Breznitz (Ed.), The denial of stress (pp. 1-30). New York: International Universities Press.

Lewin, K. (1951). Field theory in social science. New York: Harper \& Row.

Manuel, S., \& Roth, S. (1984). Coping with cancer. Manuscript submitted for publication.

McGlashan, T. H., Levy, S. T., \& Carpenter, W. T. (1975). Integration and sealing over. Archives of General Psychiatry, 32, 1269-1272.

Miller, N. E. (1944). Experimental studies of conflict. In J. McV. Hunt (Ed.), Personality and the behavior disorders (Vol. 1, pp. 431-465). New York: Ronald Press.

Miller, S. (1980). When is a little knowledge a dangerous thing? Coping with stressful events by monitoring vs. blunting. In S. Levine \& $\mathrm{H}$. Ursin (Eds.), Coping and health. New York: Plenum Press.

Miller, S., \& Mangan, C. E. (1983). Interacting effects of information and coping style in adapting to gynecological stress: When should the doctor tell all? Journal of Personality and Social Psychology, 45, 223236.

Mullen, B., \& Suls, J. (1982). The effectiveness of attention and rejection as coping styles. Journal of Psychosomatic Research, 26, 43-49.

Petrie, A. (1978). Individuality in pain and suffering. Chicago: University of Chicago Press.

Shontz, F. C. (1975). The psychological aspects of physical illness and disability. New York: Macmillan.

Staudenmeyer, H., Kinsman, R. A., Dirks, J. F., Spector, S. L., \& Wangaard, C. (1979). Medical outcome on asthmatic patients: Effects of airways hyperactivity and symptom-focused anxiety. Psychosomatic Medicine, 41, 109-118.

Zilerg, N. J., Weiss, D. S., \& Horowitz, M. J. (1982). Impact of event scale: A cross-validation study and some empirical evidence supporting a conceptual model of stress response syndromes. Journal of Consulting and Clinical Psychology, 50, 407-414. 